Military Technical College

Kobry El-Kobbah,

Cairo, Egypt

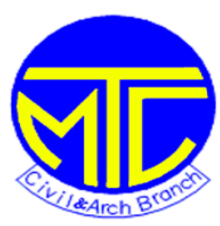

$11^{\text {th }}$ International Conference on Civil and Architecture Engineering

ICCAE-11-2016

\title{
A Review on Reinforced Concrete Beam-Column connections
}

\author{
Ahmed Asran $^{\mathrm{a}}$, Hasan Al-Esnawy ${ }^{\mathrm{b}}$ and SabryFayed ${ }^{\mathrm{c}}$ \\ ${ }^{a}$ (Prof. of Concrete Structures, Faculty of Engineering, Azhar University, Egypt.) \\ ${ }^{b}$ (Associate Professor. civil Engineering Department, Faculty of Engineering, Azhar \\ University, Egypt.) \\ c (Assistant lecturer, civil Engineering Department, kafrelkhiesh University , Egypt.)
}

\begin{abstract}
A beam-column joint is a very critical zone in reinforced concrete framed structure where the elements intersect in allthree directions.There are practical difficulties involved in theconstruction of reinforced beam-column joints.In this review to focus on the general behaviour of reinforced concrete Beam-Column joints (BCJ); exterior, interior and at top floor. Previous research work presented studying BCJ under gravity and seismic loads in addition to the effect of many parameters on the mechanical behaviour of BCJ. The current study investigated the effect of reinforcement configuration, eccentricity, the joint aspect ratio $\left(h_{b} / h_{c}\right)$, concrete compressive strength, and the compressive column axial load.BCJ classification was introduced according to ACI 318-02 (2002) and Egyptian code (2007). The equations and recommendations related with $B C J$ in national codes were reviewed.
\end{abstract}

Keywords:Strength,Ductility, Stiffness, Reinforced Concrete beam-column connection, Exterior joint, interior joint, Anchorage,cyclic loading; energy dissipation, hysteresis model,shear strength, nonseismic design,seismic design, national codes.

\section{1-Introduction}

In reinforced concrete moment-resisting frames subjectedto cyclic loading, the response, including stiffness degradation,strength degradation, and energy dissipation, is significantlyaffected by the behavior of beam-column joints.Previous research 
workfocused on studying the shear strength of the beam-column joint and the corresponding keyparameters such as the existence of joint stirrups and the beam longitudinal steel configurationwere studied by Tarek El-shafiey and et al. (2015).The design of beam-column joints is an important part of earthquake resistant design for reinforcedconcrete moment-resisting frames. Because of difficulty in repairing and retrofitting of the buildingsdamaged in beam-column joints due to the seismic attack and structural importance.The design of beam-column joints is an important part for earthquakeresistant design of reinforced concrete (RC) moment-resisting frames, sothat a lot of researches were found interested in the study of the behaviour of beamcolumn joint. The researches were found studying beam-column joint can be classified into three main categories as following,(1) the shear strength of beamcolumn joint, (2) the effect of reinforcement in thebehaviour of beam-column joint and(3) eccentric beam-column joint.

\section{2- Research Significance}

The previous earthquakes has proven that the non-design of beam column joints has greatbuilding damages. It was found that weak of the joint caused the column failure. As a result, a review state should be introduced to the behaviourof beam - column joints.

\section{3-Beam-Column Joint Classification}

based on ACI 318-02 (2002), A beam-column joint is defined as that portion of the column within the depth of the deepest beam that frames into the column. Structural connections are classified into two categories; Type 1 and Type 2 based on the loading conditions for the connection and the anticipated deformations of the connected frame members when resisting lateral loads. A Type 1 connection is composed of members designed to satisfy ACI 318-02 strength requirements for members without significant inelastic deformation. A Type 2 connection, frame members are designed to have sustained strength under deformation reversals into the inelastic range. The beam-column joints were classified regarding to their positions into six categories according to ACI 352R-2 as shown in Figure 1. 
According to Egyptian code (2007), the beam column joint divided into two types according to loads nature; Type I and Type II. Type I defined as the connections that transferred the moments and shear forces resulted from the vertical and horizontal loads such as gravity or wind load except earthquake loads. Type II defined as the connections that transferred the moments and shear forces resulted from earthquake loads.

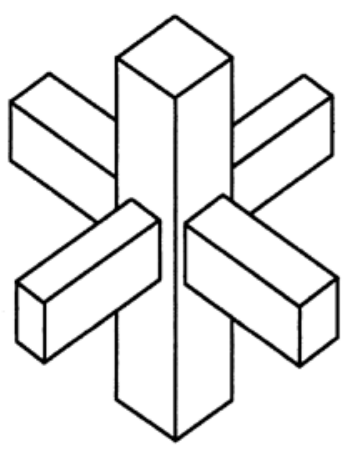

a) Interior

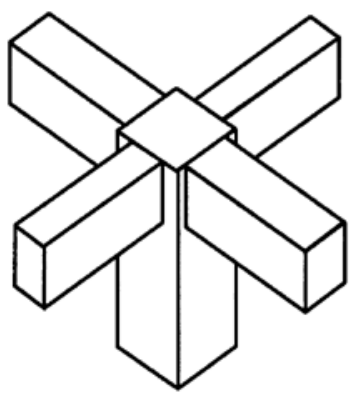

d) "Roof"-interior

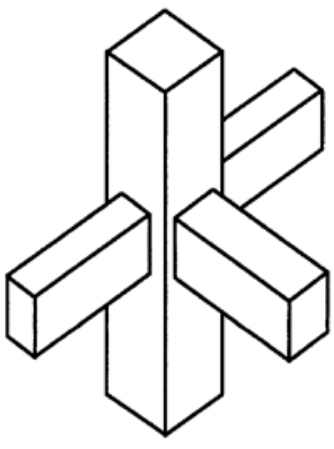

b) Exterior

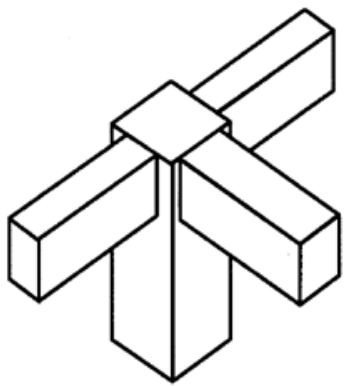

e) "Roof"-exterior

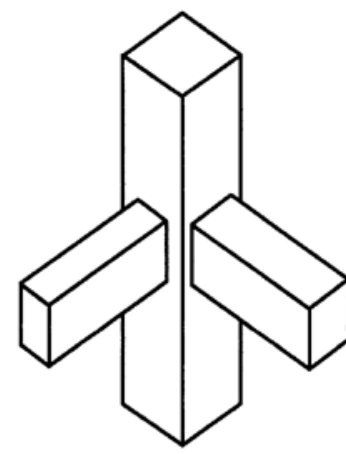

c) Corner

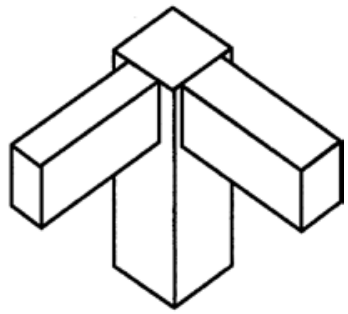

f) "Roof"-corner

Figure. 1 Joint classificationaccording to its location

\section{4-The Shear Strength of Beam-Column Joint}

YasuakiGotoand Osamu Johstudied experimentally influence of eccentricity on the shear strength of reinforced concrete interior beam-column joints. 4 specimens were tested and the test results show that as the eccentricity increased, the joint shear strength decreased.The failure mechanism of joints were studied analytically. The analytical results show that the concentration of the shear stress of joint concrete is on the eccentric side and in the region of concrete failure.Akanshu Sharma and et al. (2011) investigated strengthand ductility of RC beam-column joints of non-safety related structures and recommendations by national standards.Hideo Murakamiand et 
al.(2000) collected available 332 test data about interior R/C beam-column joint subassemblage. They studies a lot of parameters acting shear strength of interior R/C beam-column joint connection. It was showed the concrete compressive strength had biggest influence on Joint shear strength. However, column axial force ratio and joint shear reinforcement ratio were not major influencing factors.

Jaehong Kim and James M. LaFave (2007) collected andatabase of reinforced concrete (RC) beam-column connection test specimens and the specimens failed in joint shear failure. Sangjoon Park, Khalid M. Mosalam(2012) presented key parameters to determine the shear strength of exterior beam-column joints without transverse reinforcement. It showed that the shear strength of unreinforced exterior joints reduces with increase of the joint aspect ratio. The shear strength of unreinforced exterior joints is not affected by the compressive column axial load until $20 \%$ of nominal capacity.

Jung-Yoon Lee and et al. (2009) proposed a method to predict the deformability of RC joints failing inshear after plastic hinges develop at both ends of the adjacent beams. The proposed method is capable of estimating the effect of longitudinal axial strain of a beam in the plastic hinge region of the beam on the joint longitudinal strain. The estimated value of joint longitudinal strain was used to obtain the potential shear strengths of joint.

\section{5- The Effect of Reinforcement in the Behaviourof Beam- Column Joint}

F. Kusuhara1 and H. Shiohara(2008) tested a ten half-scale reinforced concrete beamcolumn joint sub-assemblages loaded to failure by statically cyclic loading simulating earthquake loading, to obtain fundamental data including stress in bars after yielding and joint deformation. The cross sections of the beams are $300 \mathrm{x} 300 \mathrm{~mm}$ and that of the columns are $300 \times 300 \mathrm{~mm}$ in all the specimens. Three sets of hoops of D6 were placed in the beam-column joints in all the specimens; the amount of joint shear reinforcement is $0.3 \%$, which is the minimum requirement of the AIJ Guidelines (1999).It was found that the story shear capacity of the specimen with transverse beams, in which the damage of the joint was severe, was improved. Also in case of damage of joints were severe, bond actions of beam bars passing through the 
joints kept lower level than the bond strength specified in the AIJ Guideline. Poor anchorage length of beam bars in exterior joints led lower story shear capacity, yielding of column bars and severe damage in the joint.

Leslie M. Megget(2004) tested afourexternal reinforced concrete beam-column subassemblages under pseudo seismic cyclic loading. Two different forms of beam bar anchorage were tested, the normal 90-degree "standard hook" and the continuous Ubar detail.It was found that the maximum beam elongations between 2.7 and 3.8\% of the beam depth were measured in all the units tested with 500E Grade beam reinforcing, about 35\% greater than those measured for the same sized beams with Grade 430 reinforcing at the same level of ductility. It was seemed to be little difference in performance between the joints withcontinuous U-bar anchorage and the more conventional standard 90-degree hook + tailanchorage. The U-bar detail has a major advantage as it reduces the complexity ofreinforcing in the joint zone, allowing easier placement and compaction of the concrete. Theadded transverse bars within the 90-degree bends to allow a reduction in the developmentlength appear to work well as no beam bar slip was apparent.

Constantin E. Chalioris and et al.(2008) investigated the effectiveness of crossed inclined bars (X-bars) as joint shear reinforcement in exterior reinforced concrete beam-column connections under cyclic deformations.the experimental study consisted of 20 joint subassemblages with various reinforcement ratios and arrangements including X-bars in the joint area. They focused full loading cycle curves, energy dissipation values and a categorization of the observed damage modes. The reinforcement details of specimens showed in figure 2. The results showed that the specimens with X-bars as the only joint shear reinforcement exhibited high values of load capacity in most of the loading cycles and increased hysteretic energy dissipation practically in the entire loading sequence. it is reported that specimens with crossed inclined bars and stirrups showed enhanced hysteretic response, excellent performance capabilities and the cracking was mainly localized in the beam-joint interface creating a distinct flexural hinge. 

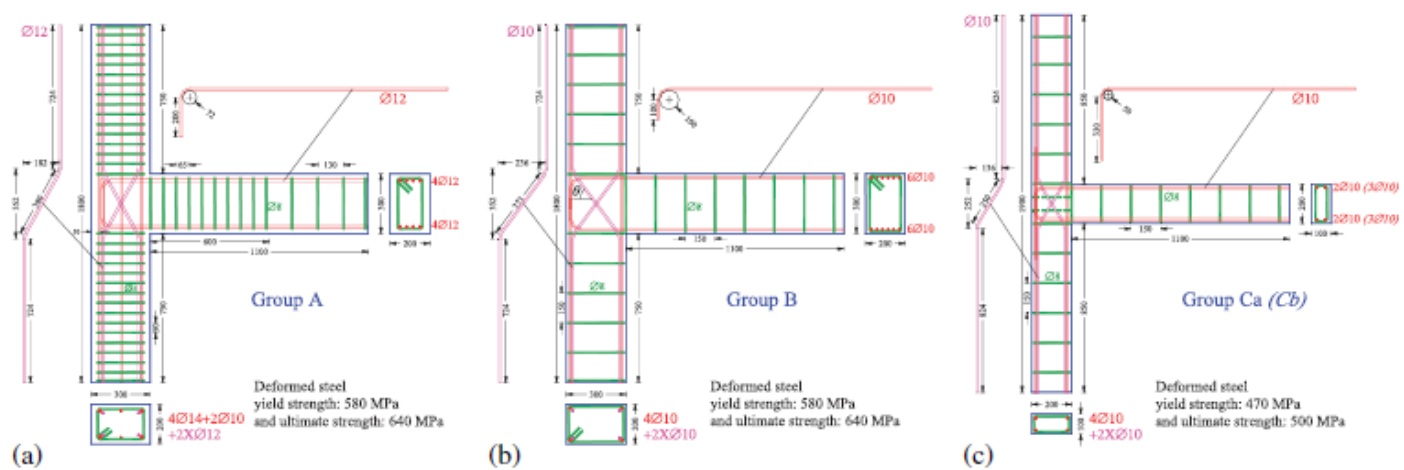

Figure 2. Geometry and reinforcement characteristics of the beam-column joint specimens [Constantin E. Chalioris and et al (2008)].

During strong earthquake, beam-column connections are subjected to severe reversed cyclic loading. If they are not designed and detailed properly, their performance can significantly affect the overall response of a ductile moment-resisting frame building. The performance of beam-column joints subjected to seismic forces may be improved only if the major design considerations are satisfied. S M Kularni and Y D Patil presented a study aimed at understanding the influence of Column crossed inclined bars on the shear strength of cyclically loaded exterior beam- column joints. They concentrated on the concrete compressive strength, the joint aspect ratio of the joints, anchorage of beam longitudinal reinforcement and amount of stirrups inside the joint. The results showed that Column crossed inclined bars was a feasible solution for increasing the shear capacity of the cyclicallyloaded beam-column joints. The presence of inclined bars introduces an additional mechanism of sheartransfer. The greater the joint aspect ratio $\left(h_{b} / h_{c}\right)$ less will be the contribution of the crossed inclined bars to the joint shear capacity. External beam-column joints with crossed inclined reinforcement showed high strength. They reached to The load resistant capacity was increased as compared to other joint configurations.

J. S. Kaung and h. F. Wong (2011) studied effectiveness of horizontal stirrups in Joint Core for Exterior Beam-Column Joints under Reversed cyclic-load with Nonseismic Design according to British standard BS 8110. It was found that horizontal stirrups which were provided in beam column joints with nonseismic design improve effectively the seismic behaviour and enhance the joint shear strength. 
It is recommended that the upper limit of the horizontal stirrup ratio in nonseismically designed exterior beam-column joints under low-to moderate seismicity for enhancing the shear capacity be $0.4 \%$. The worst scenario in this study shows that a joint fails in shear when the beam strength reached only $68 \%$ of the design flexural capacity, indicating that the joint fails when the beam is only under the service load. However, it is shown that the joints with transverse reinforcement possess much better seismic behaviour and fail after the beam strength reaches more than $83 \%$ of its ultimate flexural capacity.

Tarek El-shafiey and et al. (2015) investigated an experiments consisted of four beam column joint specimens subjected to torsional moment acting on the beam. They studied the effect of joint stirrups. The joint stirrups were designed according to Egyptian code (2007). They shed the light on the importance of longitudinal side reinforcing steel configuration.The required embedded length of the beam side and compression steel according to Egyptian code (2007) was carried as shown in figure 3. it was found that the existing of joint stirrups and developed length of beam steel transferred the failure away from the joint panel. 


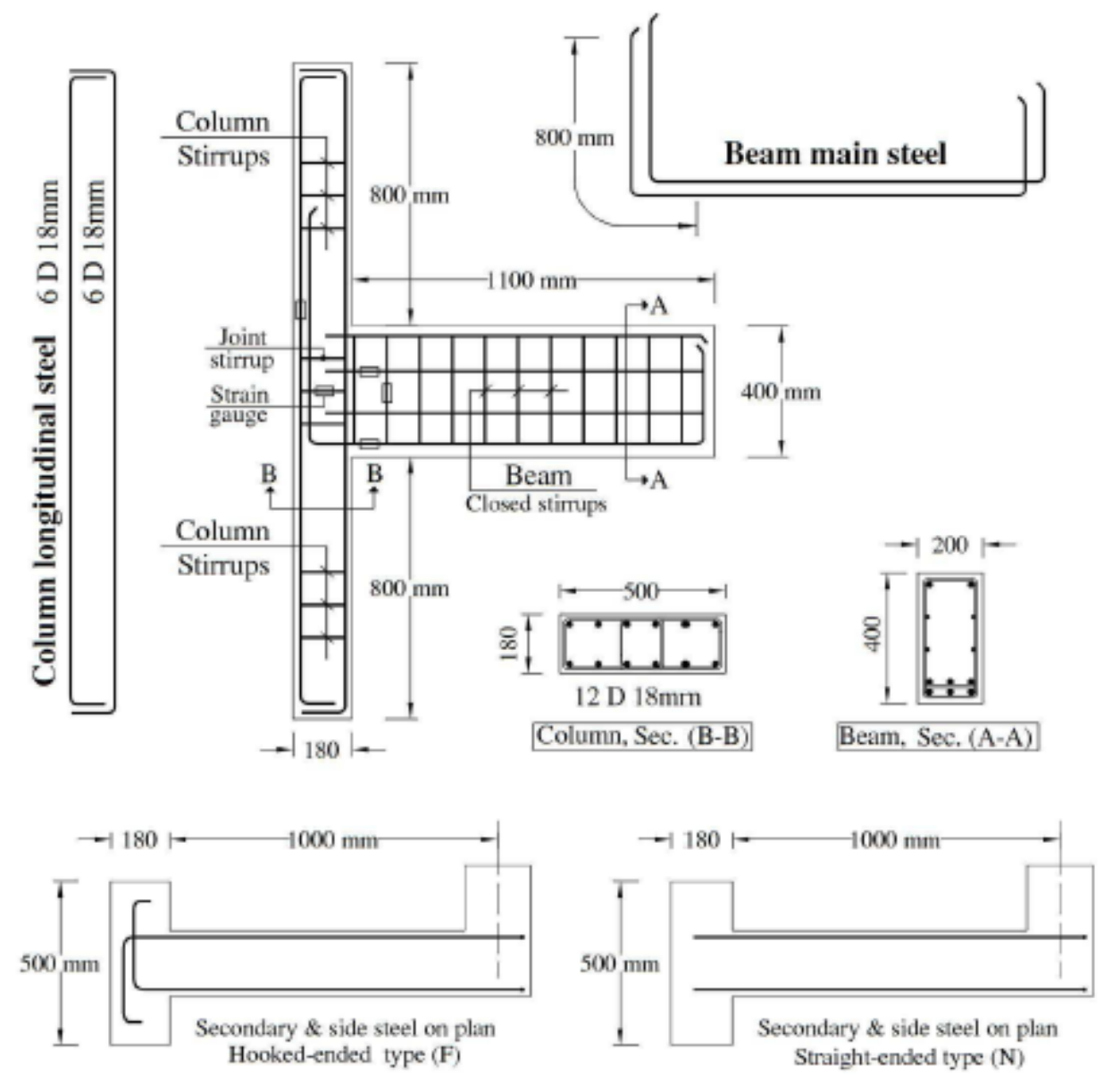

Figure 3. Reinforcement configurations for all tested specimens[Tarek El-shafiey and et al. (2015)].

Recently, the use of high-strength reinforcing bars hasincreased to save cost and to enhance constructability byreducing the number of reinforcing bars. Hyeon-Jong Hwang and et al (2014) introduced an experimental study was performed to evaluate the seismicperformance of beam-column connections using Grade $600 \mathrm{MPa}(87.0 \mathrm{ksi})$ bars for beam flexural reinforcement. To preventexcessive bond-slip, current design codes limit the columndepth to beam reinforcing bar diameter ratio $h_{c} / d_{b}$

$$
\begin{aligned}
& h_{c} / d_{b} \geq 20 \text { in Chapter } 21, \mathrm{ACI} 318-11^{1} \\
& \frac{h_{c}}{d_{b}} \geq 20 \frac{f_{y}}{420} \text { in ACI } 352 \mathrm{R}-02^{2}(\mathrm{MPa})
\end{aligned}
$$




$$
\begin{gathered}
\frac{h_{c}}{d_{b}} \geq \frac{\alpha_{0} f_{y}}{3.3 \alpha_{f} \sqrt{f_{c}^{\prime}}} \text { in NZS } 3101: 1995^{5}(\mathrm{MPa}) \\
\frac{h_{c}}{d_{b}} \geq \frac{1.25 f_{y}}{3.3 \alpha_{f} \alpha_{d} \gamma \sqrt{f_{c}^{\prime}}} \text { in NZS } 3101: 2006^{4}(\mathrm{MPa})
\end{gathered}
$$

where $\alpha_{0}$ is the coefficient related to the location of theplastic hinge of beams $(=1.0$ to 1.25); $\alpha_{f}$ is the coefficientrelated to the direction of the beam reinforcing bars; $(=0.85$ to 1.0); $\alpha_{d}$ is the coefficient related to the ductilityof the plastic hinge of beams $(=1.0$ to 1.2); $\gamma$ is the coefficientrelated to inter-story drift when the yield strength ofbeam reinforcing bars is greater than $300 \mathrm{MPa}(43.5 \mathrm{ksi})(\gamma=1.53-0.29 \delta c \leq 1.0)$; and $\delta_{c}$ is the inter-story drift ratioexpressed as a percentage.

\section{6- Eccentric Beam-Column Joint}

Usually, most of beam-column joints in a reinforced concrete (RC) building are concentric, as in the case when beam and column axes are in the same plane. For architectural reasons, however, it is not uncommon construction of eccentric beamcolumn joints in the exterior frames of RC buildings.In case of eccentric beamcolumn joint, the beam internal andexternalforces transfer through joint to the column away from its center so thata torsional moment generates along column height as shown inFigure 4.

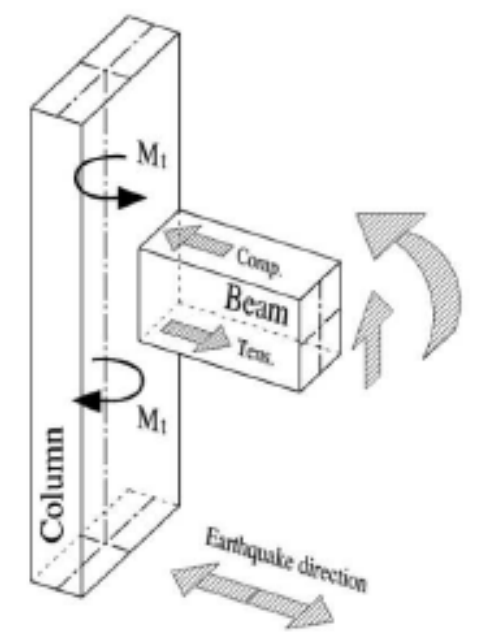

Figure.4 Torsional moment due to eccentric beam 
Analysis of building damages in earthquakes has proven that the torsional moment due to eccentric beam column joints has greatly reduced the shear capacity of the column. Jiandong Zhou and et al.(2000) studied the effect of the torsional moment, caused by the eccentric jointing of beam to column, on the shear capacity of reinforced concrete column. They introduced several typicalreinforced concrete structures damaged in the past few earthquakes such as the 1968 Tokachi-oki, the 1978 Izu-Oshima, the 1995 Hyogo-ken Nanbu, and 1997 Kagoshima-ken Hokuseibu. From theinspections of these damaged structures, it has been found that some columns in each of thesestructures were planned to joint beams to columns eccentrically. The concrete cracks, caused bythe earthquakes, appeared spirally upwards round the surface of the columns, or developed obliquely along the whole length of the columns. These cracking patterns show that the columnfailure is a kind of the torsional failure caused by the combination of torsion and shear. As a result, a particular consideration should be given to the influence of the eccentricity ofbeam column joints on the shear capacity of columns, both in seismic evaluation of existing structures and in seismic design of new reinforced concrete structures. In a column to which beams connected eccentrically, two couples of forces, as results of bending moments in the beams due to horizontal load, act at theportion apart a distance $e$ from the column center (see in Figure 4). The torsional moment works in the column can be approximately given by eq. 1

$M_{t c}=Q_{c} * e$ eq. (1)

where $Q_{c}$ is the shear force working on the column and $e$ is the eccentric distance between the beam and the column.

TomohikoKamimuraet al.(2004) carried out an experimental work to study the mechanical behavior of interior beam-column joint with the eccentricity. Experimental program was consisted of four wall girder-wide column joints with large beam depth and two beam-column joints which beam depth is the same as column depth. The ultimate strength of wide column under combined torsion and shear increases with the amount of column longitudinal reinforcement and joint lateral reinforcement. Fig.7 shows failure pattern of specimen No.2 without eccentricity. it was concluded that the failure mode of specimen No.2 was the joint shear failure after beam and column flexural yielding. Failure pattern at the ultimate stage of representative No.4 specimen with eccentricity is shown in Figure.5. In this 
specimens, although the side face of the column near the wall girder was heavily damaged, the side face far from the beam suffered rather minor cracks. Therefore, it was concluded that the failure mode of specimen was the column failure under combined shear and torsion.

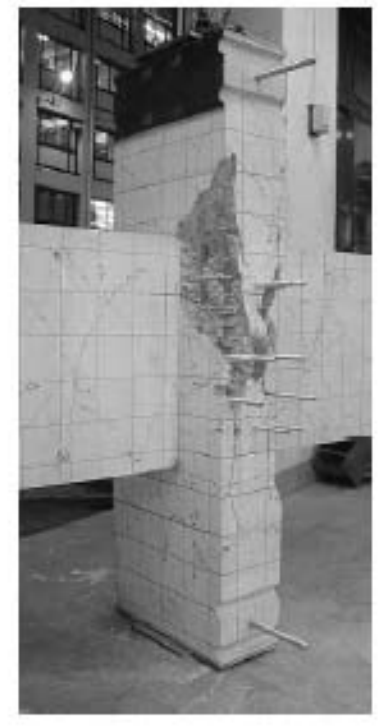

No.2

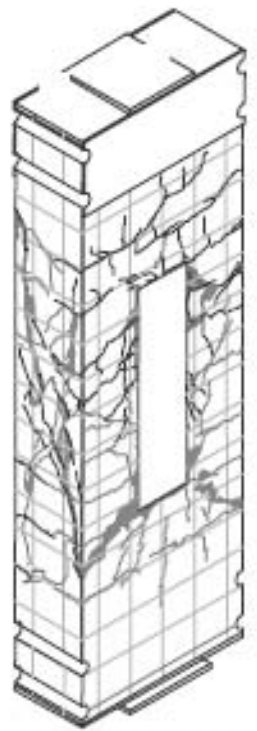

No.2

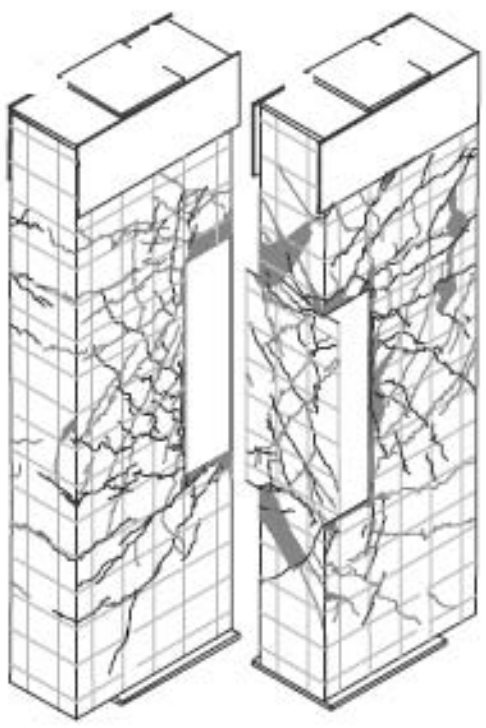

No.4

Figure.5 Crack patterns at final stage in representative specimens of wall girder-wide column Assemblages[TomohikoKamimuraet al.(2004)].

Ineccentric beam-column joints, the axis of the spandrel beams is offset from the axis of column. As forthese eccentric joints subjected to earthquake loads, it was considered that additional shear forces,produced by torsion moment from beams, severely act on the joints. Moreover, brittle shear failures ofeccentric joints subjected to additional shear forces were observed from the previous earthquake damages. the effect of eccentricity on degradation of shear strength, stiffness and deformation capacity of beam-column joints have been carried out by Takashi Kashiwazakiand Hiroshi Noguchi(2004).

Fumio Kusuharaand et al. (2004), investigated experimental work consisted of three specimens of one third scale reinforced concrete interior beam-column subassembladges were loaded to failure by statically cyclic load simulating earthquake, to obtain fundamental data including three dimensional deformation of beam-column joint. The test results indicated that the eccentricity in the joints led to lower capacity 
in story shear and severe damage of concrete on the side to which the center line of beam shifted to.

BurcuBurakand james k. wight(2004) investigated the seismic behavior of three 3/4scale eccentric beam-column-slab subassemblies. They focused on the eccentricity, normal beam width, and column section aspect ratio. Three exterior reinforced concrete beam-column-slab subassemblies were tested under reversed cyclic loading. Each specimen consists of top and bottom columns, two spandrel beams, a normal beam, and afloor slab. They were loaded initially in the spandrel beam direction (Fig. $6 a)$, then they were rotated 90 degrees and loaded in the normal beam direction (Fig. $6 b)$.

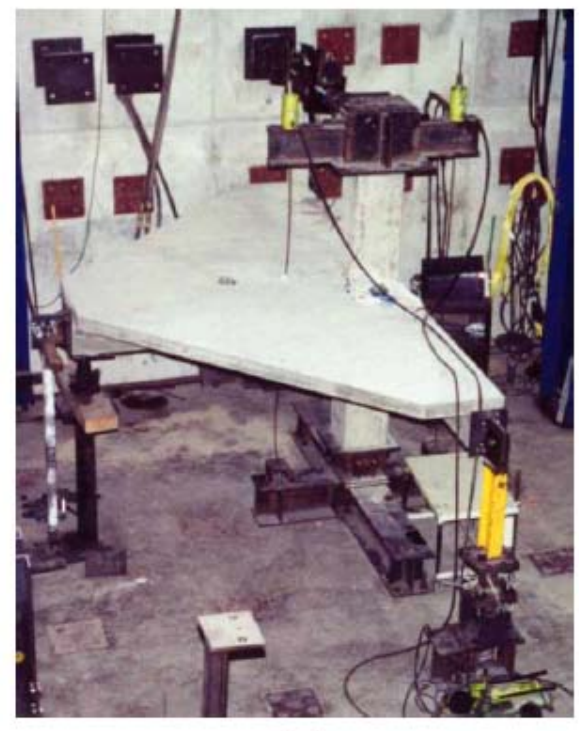

(a)

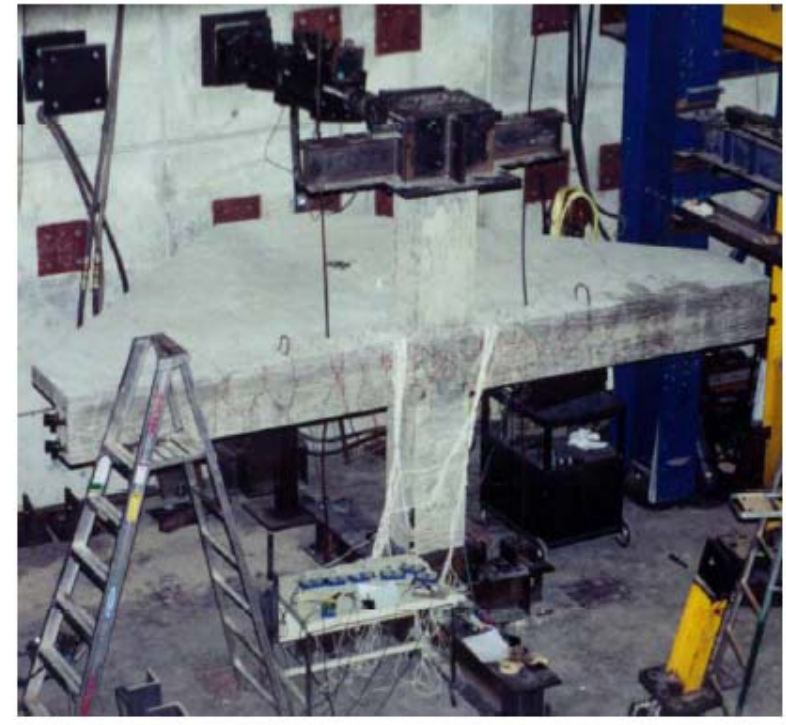

(b)

Figure.6 Loading of Specimens in (a) Spandrel and (b) Normal Beam Directions[BurcuBurak and james k. wight(2004)].

Tarek El-shafiey and et al. (2015) presented an experimental program consisted of Four beam columnjoint specimens were constructed and tested up to failure in order to better understandthe complicated behaviour due to combined loading transmitted from the beam to the column. The studied parameters were the configuration of beam side and compression reinforcement andthe existence of the joint reinforcing stirrups. Straight-ended side steel configurations of the beam provided lower response of thejoint and led the specimen to fail at beam zone due to shear stresses. Thus, hooked endedside steel configurations enabled the specimens adopting this configuration 
tooutperform their response and were more efficient to transfer the straining actionfrom the beam to the joint panel.

\section{7- Behaviour of RC Beam Column Joint UnderGravity Loads.}

Reinforced concrete structures frequently are constituted of a beam-column subassemblage with different floorlevels on both sides of column. The equations of joint shear strength for the shape of exterior and interior joint are proposed. But these proposed equations do not reflect the influence of the distance between one beam axis and the other beam axison both sides of column. So the mechanical behavior of beamcolumn subassemblage with different floor levels on both sides of column was studied by TomohikoKamimura (2008). The effect of joint failureafter beam yielding on frame behavior and the effect of membrane action or arching action on the behaviour of reinforced concrete frames were examined by A.W. Beeby (2001) and Osamu Joh(2000).Lack of transverse beam-column joint reinforcement, use of plain bars for longitudinal reinforcement, pooranchorage detailing, and low concrete strength are the most common deficiencies of pre 1970s reinforced concrete framestructures [Ravi Kiranand GiovacchinoGenesio (2014)].RC exterior beam-column joint at top floor which is called L-joint was investigated by Hiroshi Okano and et al (2004). Abdel Rahman M. Ahmed and et al. (2012) introduced a theoretical study of the effect of both acting axial loads and grade of concrete on the static behaviour of Reinforced Concrete (RC) Beam-column joints.A lot of the parameters such as ductility, stiffness, anchorage, exterior joint, bond, confined concrete, high-strength concrete, joints, reinforced concrete, reinforcing steel, shear strength, and shear stress were studied by A.K.Kaliluthin and et al (2014) and Joint ACI-ASCE Committee 352(2002).

\section{8- Seismic Behaviour of RC Beam Column Joint}

structures and lifelines designed for typical loading are often badly damaged or can collapse during earthquakes. the observations from recent earthquakes show that many RC structures have failed in the brittle behaviour of beam-column connections due to the deficiency of seismic details in the joint regions. Joint shear failures have been observed recently in many existing RC structures subjected to severe earthquake loadings. The seismic performance of reinforced concrete beam_column connectionswas investigated experimentally by many researchers such as 
MinakshiVaghaniand et. al (2015), A. Benavent-Climentand et. al (2009), A.M. Elsouriand M.H. Harajli(2013) . The study included the following parameters: strength, displacement, ductility and energy dissipation capacity, drift reversals, reinforcement detailing requirements. Leslie M. Meggetand et. al (2004) introduced a study on seismic design and behavior of external reinforced concrete beam-column joints using 500E grade steel reinforcing. They focusedon two different forms of beam bar anchorage were tested, the normal 90-degree "standard hook" and the continuous U-bar detail.In all units thefarthest point of the beam bar anchorage was positioned at the minimum limit prescribed inthe NZ Concrete Standard (NZS3101), namely $3 / 4$ of the column depth from the inner columnface.

Recent earthquakes have shown that beam-column joint performances can have a remarkable influence on the strength and overall stability of reinforced concrete(RC) framed structures. Design procedures of new buildings and assessment procedures of existing ones provided in past seismic codes have generally focused on structural members such as beams and columns and paid less attention to the beam-column intersection region (joint panel).So, analysis of some test results obtained in the framework of a wide experimental program on RC beam-column joints carried out by Angelo Masiand etal. (2013) and effect of axial load ratio on seismic behaviour of interior beam-column joints carried out by Jianping Fu and etal. (2000).

Reinforced concrete frames constructed prior to the 1970s are susceptible to damage under seismic loading. Joints in these frames may be subjected to high shear stresses. In current seismic design, limits on joint shear stresses play a dominant role in determining the column size in reinforced concrete frames. seismic performance of older beam-column joints was proposed by Dawn Lehmanand etal.(2004).Although, the current ACI requirements, viewing the joint hoop as confining the concrete core, are unnecessary and very difficult for construction, Shyh-Jiann Hwang and etal.(2004) investigated the effect of joint hoops on the shear strength of exterior reinforced concrete beam-to-column connections subjected to earthquake loading. The results showed the joint hoops are found to act as a tension tie as well as to constrain the crack width.

There are a lot of many researches in the field of seismic analysis for reinforced concrete exterior and interior beam-column connections. The researchers studied 
many parameters. The failure mode and the bond slip of beam flexural bars and joint shear deformations that occur at the joint panel were investigated by YoshimasaOwada(2000) andTae-Sung Eom and et al (2015).A model was developed to represent the response of reinforced-concrete beam-column joints under reversedcyclic loading and this model was proposed by Laura N. Lowes and ArashAltoontash (2003). Ductile fiber-reinforced cement-based composites are being investigated for the design and retrofit of structures undersevere loading conditions. The material has significantly greater ductility than plain concrete [Tong-Seok Han (2003)]. Experimental verification of reinforced concrete member under cyclic loadingwas proposed by Alenaavojcová (2014).The effect of cyclic loading on RC concrete member (beams, columns and beam-column joints) was studied by some researchers such as Y.Y. Chang and et al (2003) , M.N. Fardis (2009) and Zheng Li and et al (2012).

Rajesh Prasad Dhakal and et.al (2005) conducted cyclic loading tests of full-scale RC beam-column sub-assemblies. Gradually increasing displacement cycles were applied at different speeds to the specimens, which were designed only for gravity loads and hence had no hoops inside the joint cores. They reached that when gravity-designed $\mathrm{RC}$ frames with the joint as the weakest component are subjected to lateral actions, they experience severe damage in the joint panels and ultimately suffer joint shear failure before the formation of a plastic hinge in the adjoining members.

\section{9-Seismic Loads Simulation in RC Beam Column Joint}

The seismic behaviour of reinforce concrete exterior wide beam-column connections is investigated through computational simulations using ABAQUS[S.H. Lukand J.SKuang (2012)]. The loading schedule in this study includes two steps. First,constant column axial load is applied at the top of the column. Second, the bottom end of the column is displaced laterally following the pattern (as shown in Figuer. 7) to simulate the working condition of the beam-column assemblies under load reversals. 


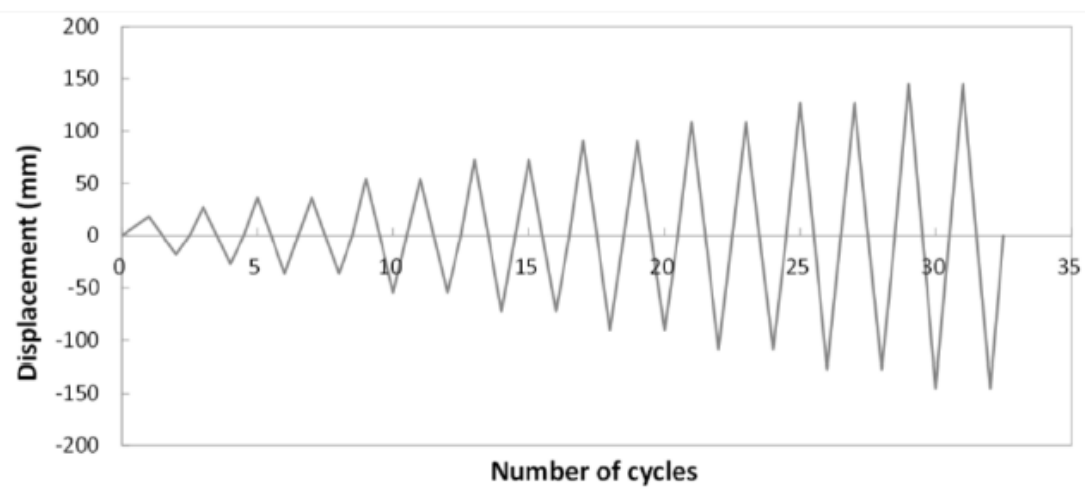

Figure 7.loading schedule [S.H. Luk and J.SKuang (2012)].

MinakshiVaghani and et al (2015) introduced an experimental investigation of RC beam column specimen tested cyclic loading. A two set of hydraulic jack were employed to apply reversible cyclic loading at the bean end. Gradually, increasing reversed cyclic loading was applied at the top of the beam, with the displacement increment in each step being $5 \mathrm{~mm}$. The $5 \mathrm{~mm}$ displacement indicates $5 \mathrm{~mm}+\mathrm{ve}$ as well as -ve displacement. The increment of $5 \mathrm{~mm}$ displacement was given in consecutive cycle up to the failure as shown in figure 8.

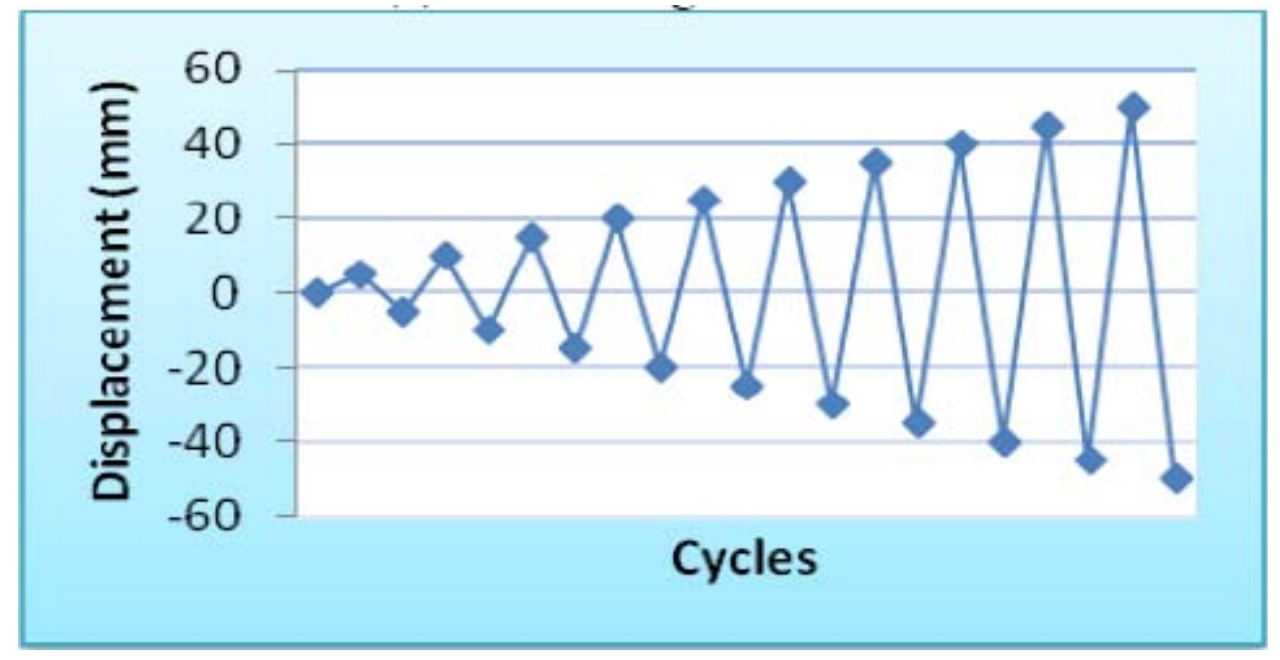

Figure 8Cyclic load history [MinakshiVaghani and et al (2015)].

A.DalalBashi and et al (2011) proposed a numerical investigation of RC beam column connection tested under cyclic loading. Figure 9 showed the loading cyclic. 


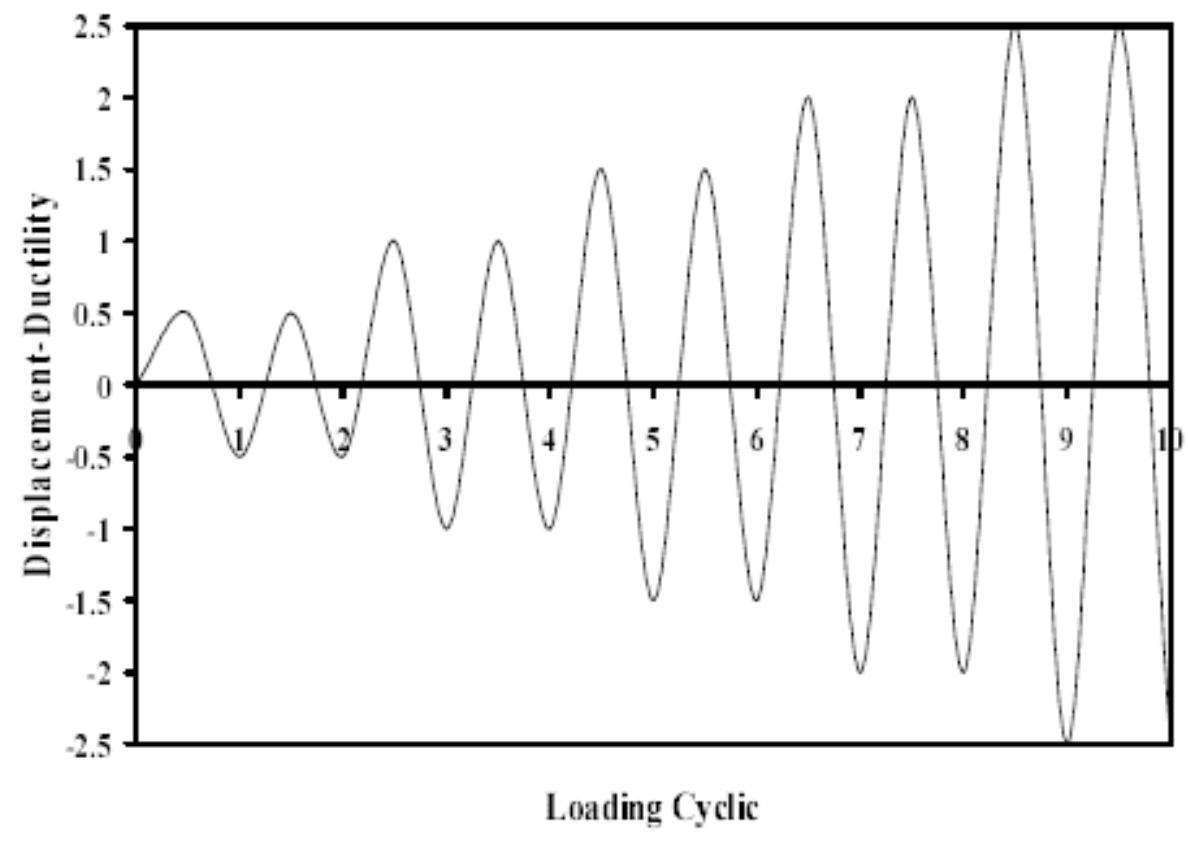

Figure 9analytical loading regime [A. DalalBashi and et al (2011)].

\section{0- Egyptian Code Equations and recommendations for Beam Column Joints.}

It recommended that the longitudinal bars of beam should extended developedlength from centroid of column. The forces acting on the connection are shown in figure 10. It was recommended that maximum shear force $\left(Q_{\mathrm{uj}}\right)$ acting on the connection not exceeded nominal shear strength which calculated from Eq. (2).The maximum shear force on beam column joint estimated from Eq. (3).

$\mathrm{Q}_{\mathrm{uj}} \leq \mathrm{K}_{\mathrm{j}} \mathrm{A}_{\mathrm{j}} \sqrt{\frac{f_{c u}}{\gamma_{c}}} \quad$ eq. (2)

$\mathrm{Q}_{\mathrm{uj}}=\frac{f_{y} \lambda A_{s u}}{\gamma_{s}}+\frac{0.67 b f_{c u} a_{t}}{\gamma_{c}}+A_{s u} f_{s t}-Q_{u c o l} \quad$ eq.(3)

Where $\mathrm{K}_{\mathrm{j}}$ factor of confinement degree for joint and it was estimated according to connection type I or II and number of beams connected by columns in addition to is column continuous or top floor. $A_{j}$ isarea of effective cross-section through joint panel and it was defined as the area which resist shear force in load direction. The depth of joint is overall thickness of the column (h) and the effective width of joint equal the least of $\mathrm{h}+\mathrm{b}$ or $\mathrm{b}+2 \mathrm{x}$ as shown in figure.11. $f_{\mathrm{cu}}$ is compressive strength of concrete (MPa) , $\gamma_{c}$ is reduction factor of concrete. $\lambda=1$ for type I and $\lambda=1.25$ for type II. $f_{s t}$ is the stress in compression steel of beam. 


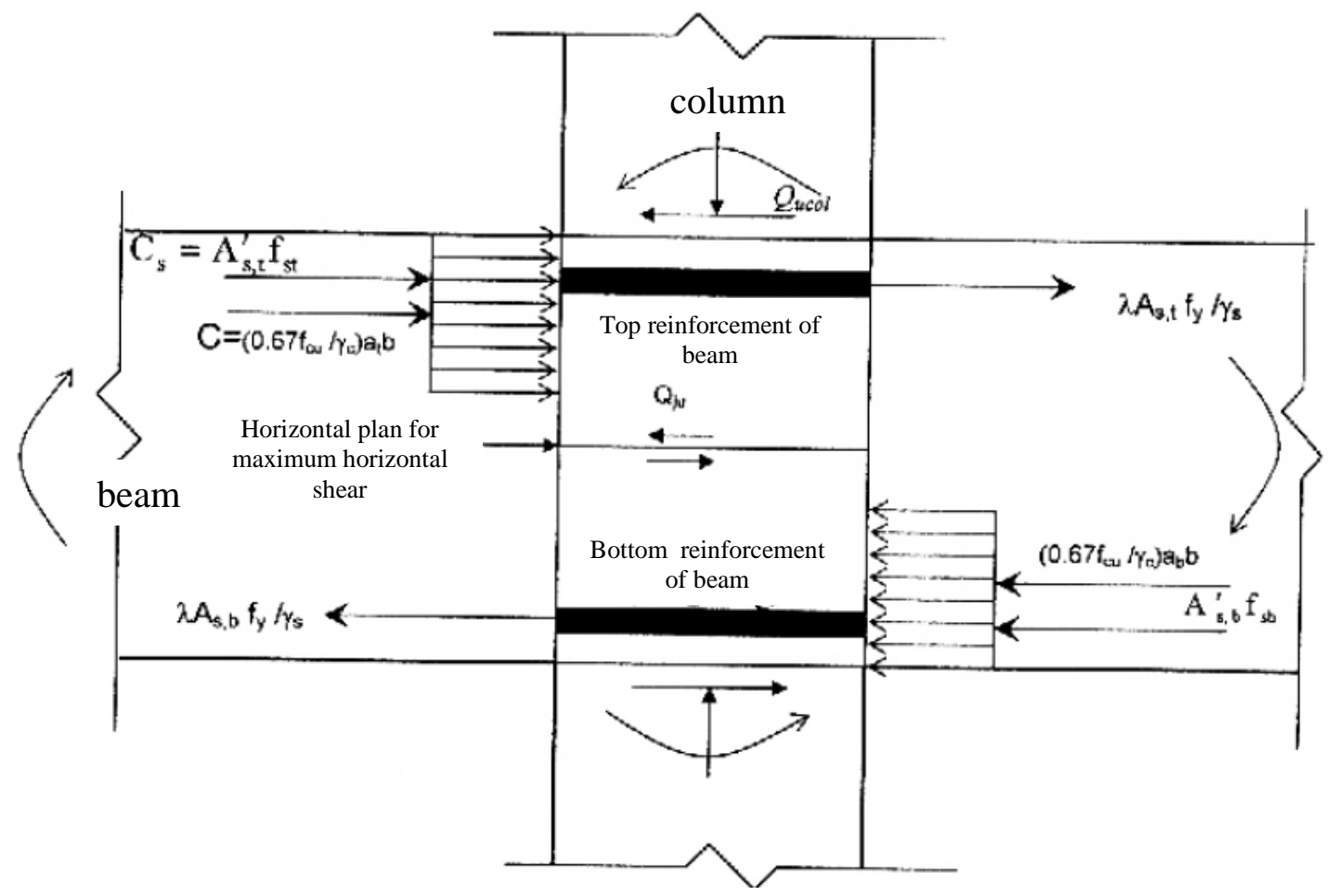

Figure.10 the forces acting on the connection[ECP(2007)].

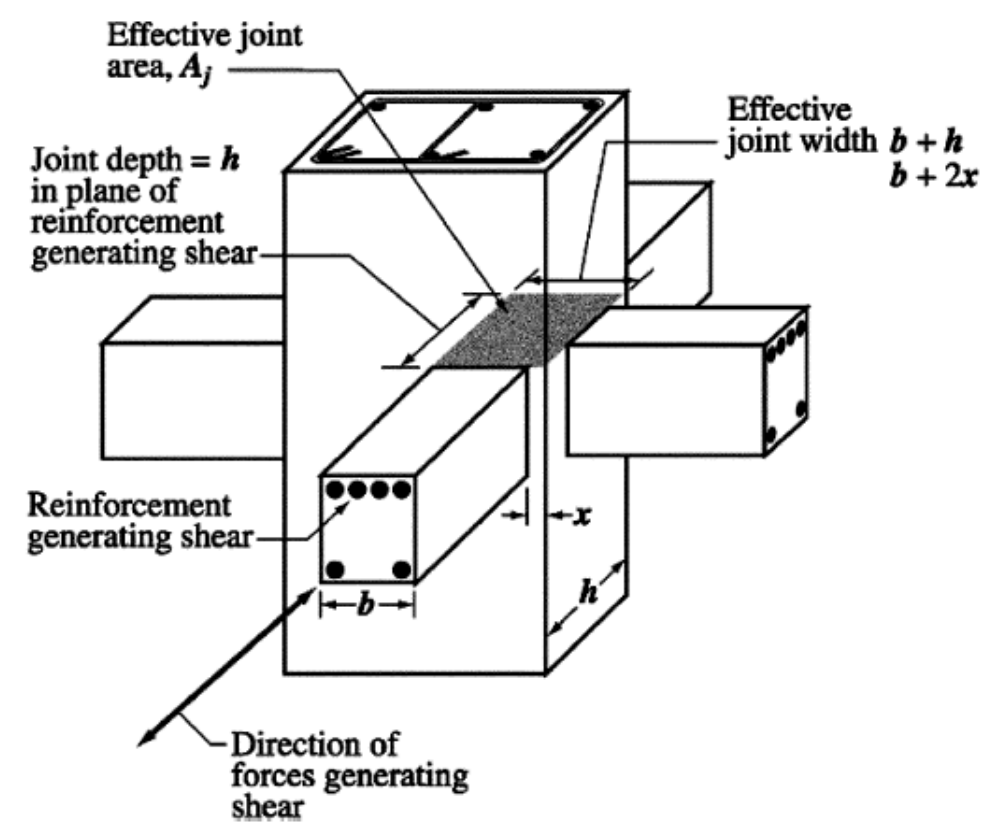

Figure 11 effective area $\left(A_{j}\right)$ of beam column connection[ECP(2007)].

The column stirrups must to be extended inside the joint panel and not less than the following value (Eq.(4) or Eq.(5)):

$A_{s t}=0.313\left(\frac{\left(f_{c u} / \gamma_{c}\right) s \cdot y_{1}}{\left(f_{y s t} / \gamma_{s}\right)}\right)\left[\left(\frac{A_{g}}{A_{k}}\right)-1\right] \quad$ Eq.(4) 
$A_{s t}=0.1\left(\frac{\left(f_{c u} / \gamma_{c}\right) s \cdot y_{1}}{\left(f_{y s t} / \gamma_{s}\right)}\right) \quad$ Eq.(5)

Where $A_{g}$ is the total area of cross section. $A_{k}$ is cross-section area of structural element (core of column) inside parameter of outer stirrup. $f_{y s t}$ is yield strength of stirrup. $\mathrm{S}$ is spacing between stirrup measured in longitudinal axis of column. $\mathrm{y}_{1}$ is dimension of columncore measured perpendicular on beam axis. $A_{s t}$ is the total area of stirrups branches including perpendicular branches through distance $S$ and perpendicular on $\mathrm{y}_{1}$.

\section{1- ACI Code Equations and recommendations for Beam Column Joints}

Recommendations are given for member proportions, confinement of thecolumn core in the joint region, control of joint shear stress, ratio of columnto-beam flexural strength at the connection, development of reinforcingbars, and details of columns and beams framing into the joint.The recommendations are based on laboratory testing and field studiesand provide a state-of-the-art summary of current information.

\subsection{Design forces in joint panel}

The connection should resist all forces that may be transferredby adjacent members, using those combinations thatproduce the most severe force distribution at the joint, including the effect of any member eccentricity.Design recommendations are based on the assumptionthat the critical sections are immediately adjacent to thejoint. Exceptions are made for joint shear and reinforcementanchorage. Figure 12 shows the joint as a free body withforces acting on the critical sections.

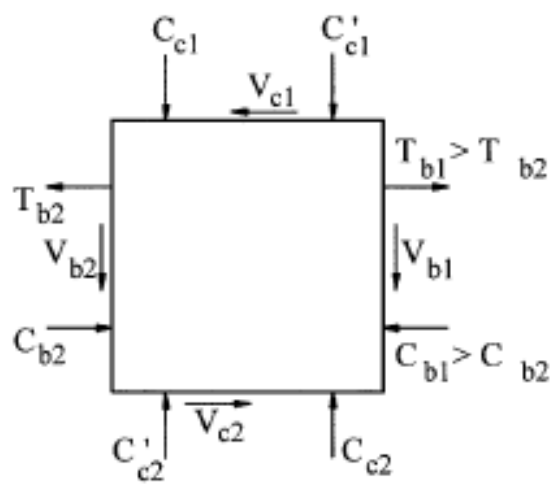

(a) Due to gravity loads

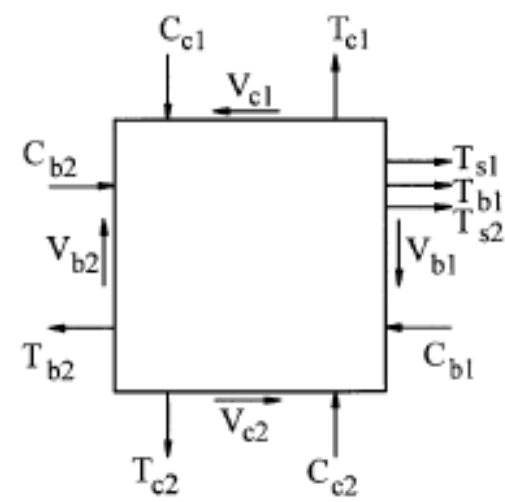

(b) Due to lateral loads 
Figure.12 Joint forces at critical sections. $\mathrm{T}=$ tension force;

$\mathrm{C}=$ compression force; $\mathrm{V}=$ shear force; subscript $\mathrm{b}$ for beam; subscript c for column; and subscript s for slab[ACI 318-02].

\subsection{Requirements ofReinforcement Detailing}

For Type 1 connections, longitudinal column bars may beoffset within the joint. The provisions of ACI 318-02 foroffset bars should be followed.For Type 2 connections, longitudinal column barsextending through the joint should be distributed around the perimeter of the column core. Further, the center-to-centerspacing between adjacent column longitudinal bars shouldnot exceed the larger of $8 \mathrm{in}$. $(200 \mathrm{~mm})$ and 1/3 of the columncross-section dimension (or diameter) in the direction thatthe spacing is being considered.Longitudinal column barsmay be offset within the joint if extra ties were used.Transmission of the column axial load through the jointregion, and transmission of the shear demand from columnsand beams into the joint, require adequate lateral confinementof the concrete in the joint core by transverse reinforcement.For Type 1 connections, When spiral transverse reinforcement is used, thevolumetric ratio $\rho_{s}$ should not be less than the following value eq.(6)

$\rho_{\mathrm{s}}=0.45\left(\frac{A_{g}}{A_{c}}-1\right) \frac{f_{c}}{f_{y h}} \mathrm{eq} .(6)$

When ties or spirals are recommendedin a joint that is part of the primary system for resistingnonseismic lateral loads, the recommended spacing or spiralpitch is limited to $150 \mathrm{~mm}$, center-to-center, to provideadditional confinement to the joint.

For Type 2 connections, When spiral transverse reinforcement is used, thevolumetric ratio $\rho_{\mathrm{s}}$ should not be less than the following value eq.(7) but should not be less than eq.(6)

$\rho_{\mathrm{s}}=0.12 \frac{f_{c}}{f_{y h}} \quad$ eq.(7)

When cross tie horizontaltransverse reinforcementis used, the total cross-sectional area in each directionof a single hoop, overlapping hoops, or hoops withcrossties of the same size should be at least equal to eq.(8)

$\mathrm{A}_{\mathrm{sh}}=0.3\left(\frac{A_{g}}{A_{c}}-1\right) \frac{s_{h} b_{c} f_{c}}{f_{y h}}$ eq.(8)

but should not be less thaneq.(9)

$\mathrm{A}_{\mathrm{sh}}=0.09 \frac{s_{h} b_{c} f_{c}}{f_{y h}} \mathrm{eq} .(9)$ 
For connections composed of members that arepart of the primary system for resisting seismic lateral loads,the center-to-center spacing between layers of horizontaltransverse reinforcement (hoops or hoops and crossties) should not exceed the least of $1 / 4$ of the minimum columndimension, six times the diameter of longitudinal columnbars to be restrained, and 6 in. (150 mm).Recommended shapes of closed hoops and single-legcrossties are shown in Figure 13. The preferred shape for asingle-leg crosstie would have a 135-degree bend at bothends.

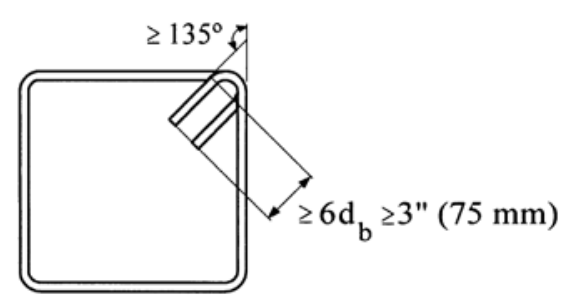

a) Closed Hoop

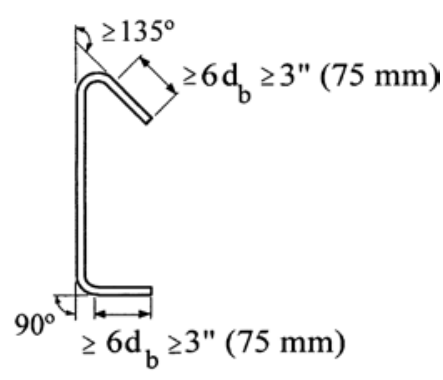

b) Single Leg Cross Tie

Figure.13Required dimensions of transverse reinforcement [ACI 318-02].

\subsection{Joint shear force for Type 1 and Type 2 connections}

Thedesign shear force $\mathrm{V}_{\mathrm{u}}$ should be computed on a horizontalplane at the midheight of the joint by considering the shearforces on the boundaries of the free body of the joint as wellas the normal tension and compression forces in the members framing into the joint. The following equation eq.(10) should be satisfied

$\phi \mathrm{V}_{\mathrm{n}} \geq \mathrm{Vu}$ eq.(10)

where $\phi=0.85$ and $V_{n}$, the nominal shear strength of the joint, is determined from eq.(11)

$\mathrm{V}_{\mathrm{n}}=\gamma \sqrt{f_{c}} b_{j} h_{c}$ (psi)eq.(11)

whereb $b_{j}$ is the effective joint width and $h_{c}$ is the depth of the column in the direction of jointshear being considered.The constant $\gamma$ is given in Table 1 and depends on the connection classification and connection type.The typical procedure for calculating the horizontaldesign shear in an interior and an exterior connection isshown in Figure14.

Table 1-Values of $\gamma$ for beam-to-column connections

\begin{tabular}{|l|c|c|}
\hline \multicolumn{1}{|c|}{ Classification } & \multicolumn{2}{c|}{ Connection type } \\
\cline { 2 - 3 } & \multicolumn{1}{|c|}{1} \\
\hline \multicolumn{2}{|c|}{ A. Joints with a continuous column } \\
\hline $\begin{array}{l}\text { A.1 Joints effectively confined on all four vertical } \\
\text { faces }\end{array}$
\end{tabular}


A.2 Joints effectively confined on three vertical faces or on two opposite vertical faces

A.3 Other cases
20

15

B. Joints with a discontinuous column

B.1 Joints effectively confined on all four vertical

faces

B.2 Joints effectively confined on three vertical

faces or on two opposite vertical faces

B.3 Other cases

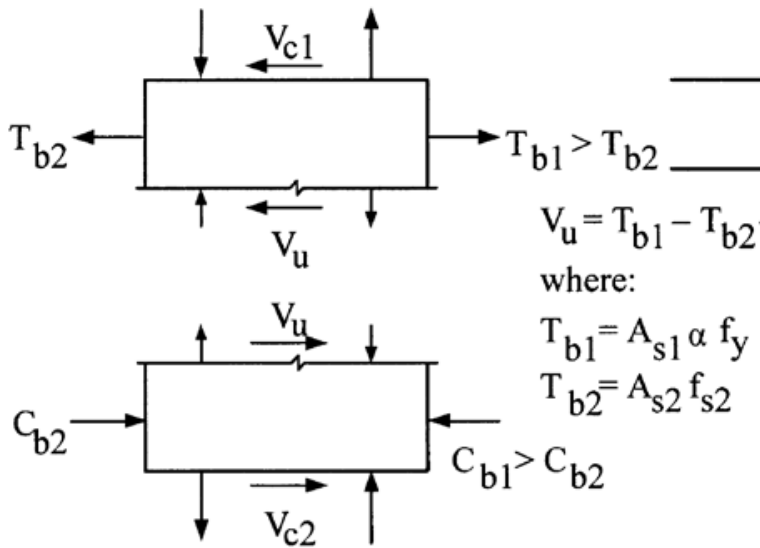

Joint Elevation

(a) Type 1 connection
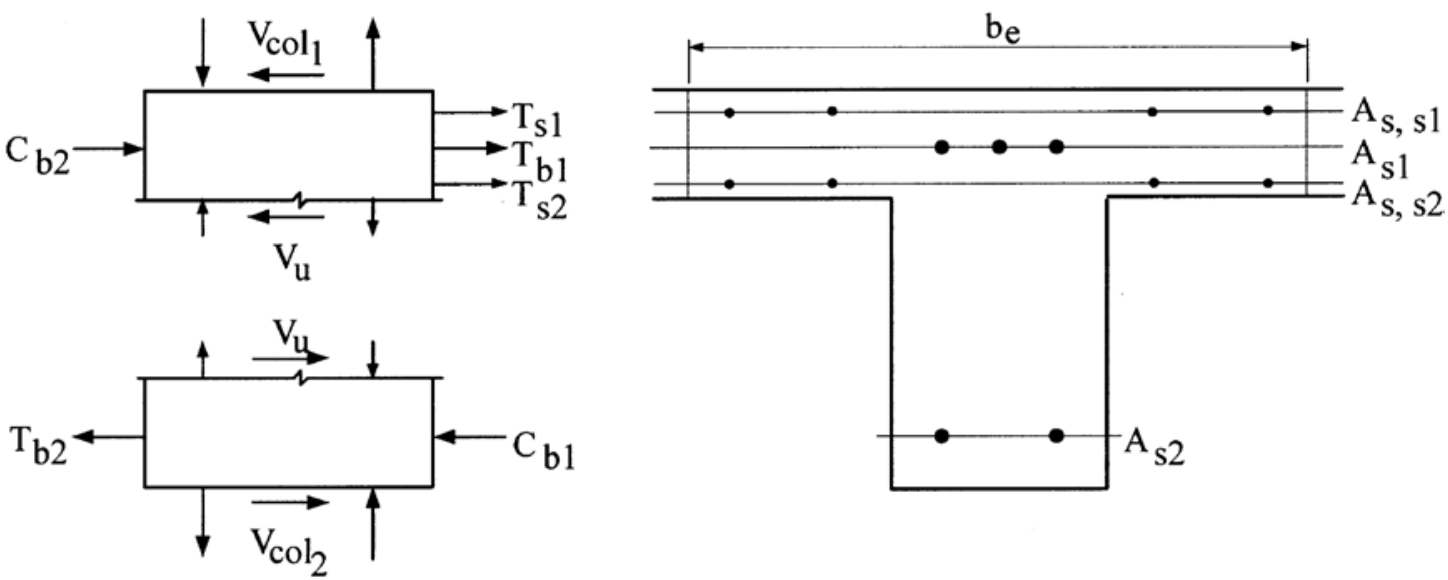

Joint Elevation
12
Beam Section

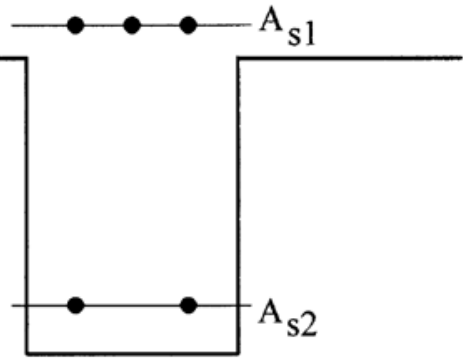

Beam Section

$\mathrm{V}_{\mathrm{u}}=\mathrm{T}_{\mathrm{b} 1}+\mathrm{T}_{\mathrm{s} 1}+\mathrm{T}_{\mathrm{s} 2}+\mathrm{C}_{\mathrm{b} 2}-\mathrm{V}_{\mathrm{col}}$

where:

$\mathrm{T}_{\mathrm{b} 1}+\mathrm{T}_{\mathrm{s} 1}+\mathrm{T}_{\mathrm{s} 2}=\alpha_{\mathrm{f}_{\mathrm{y}}}\left(\mathrm{A}_{\mathrm{s} 1}+\mathrm{A}_{\mathrm{s}, \mathrm{s} 1}+\mathrm{A}_{\mathrm{s}, \mathrm{s} 2}\right)$

$\mathrm{C}_{\mathrm{b} 2}=\mathrm{T}_{\mathrm{b} 2}=\mathrm{As}_{\mathrm{s} 2} \alpha \mathrm{f}_{\mathrm{y}}$

(b) Type 2 connection

Fig. 14 Evaluation of horizontal joint shear

\subsection{Areas Needing Research}


The following list identifies areas needing further research: Effect of eccentric beams on joints, Lightweight aggregate concrete in joints, Limit on joint shear, Behavior of indeterminate systems, Distribution of plastic hinges, Innovative joint designs, Special joint configurations and loadings, and Joints in existing structures.

\section{2-CONCLUSION}

The beam column connection is the most important region in reinforced concrete structures practically, in case of earthquakes. This research introduced a literature review on the beam column connection under gravity and seismic loads. The review included the previous works either experimental or numerical study in addition to recommendations of national codes. Based on the results of this investigation, the following conclusions or observations can be drawn:

1- The beam column connection was classified to two types; type I designed to resist straining actions due to gravity loads, while type II designed to resist straining actions due to earthquake loads.

2- The concrete compressive strength had bigger influence on Joint shear strength than column axial force ratio and joint shear reinforcement ratio.

3- the compressive column axial load, that was lower than $20 \%$ of nominal capacity, did not affected on the shear strength of unreinforced exterior joints.

4- the minimum amount of joint shear reinforcement is $0.3 \%$ according to the AIJ Guidelines (1999).

5- Use of X-bars as joint shear reinforcement enhance hysteretic energy dissipation.

6- the joint without stirrups fails in shear when the beam strength reached only $68 \%$ of the design flexural capacity,while it is shown that the joints with transverse reinforcement possess much better seismic behaviour and fail after the beam strength reaches more than $83 \%$ of its ultimate flexural capacity.

7- the eccentricity in the joints led to lower capacity in story shear and severe damage of concrete on the side to which the center line of beam shifted to. 


\section{3-REFERENCES}

[1] ACI 352R-2, "Recommendations for design of beam columnconnections in monolithic reinforced concrete structures”, becomeeffective June 18, 2002.

[2] Chalioris, C. E., Favvata, M. J., and Karayannis, C. G., (2008),“Reinforced concrete beam-column joints with crossed inclined barsunder cyclic deformations", Earthquake Engineering and StructuralDynamics, Vol. 37, pp. 881-897.

[3] MinakshiVaghani , Dr. S.A. Vasanwala , Dr. A.K. Desai (2015) ," Performance of RC Beam Column Connections Subjected to Cyclic Loading " IOSR Journal of Mechanical and Civil Engineering, Volume 12, Issue 2 Ver. VII (Mar - Apr. 2015), PP 48-53.

[4] Egyptian Code for Design and Construction of Reinforced ConcreteStructures, (ECP 203-2007) 2007.

[5] Fu, J., Chen, T., Wang, Z., and Bai, S., (2000), "Effect of axial loadratio on seismic behaviour of interior beam-column joints", the 12thworld conference of earthquake engineering, Paper No. 2707.

[6] Goto, Y., and Joh, O., (2004), "Shear resistance of RC interioreccentric beamcolumn joints”, the 13th world conference ofearthquake engineering, Paper No.649.

[7] Hwang, S. J., Lee, H. J., and Wang, K. C., (2004), “Seismic designand detailing of exterior reinforced concrete beam-column joints", the 13th world conference of earthquake engineering, Paper No. 397.

[8] Joh, O., and Goto, Y., (2000), "Beam-column joint behavior afterbeam yielding in RC ductile frames", the 12th world conference ofearthquake engineering, Paper No. 859.

[9] Kamimura, T., Ishibashi, K., and Fujitsuka, M., (2008), "Mechanicalbehavior of reinforced concrete beam-column assemblage withdifferent floor levels on both sides of column”, the 14th worldconference of earthquake engineering.

[10] Kamimura, T., Takimoto, H., and tanaka, S., (2004), "Mechanicalbehavior of reinforced concrete beam-column subassemblages witheccentricity", the 13th world conference of earthquake engineering,Paper No.4.

[11] Kashiwazaki, T., and Noguchi, H., (2004), "Seismic performanceevaluation of RC eccentric beam-column joints using three-dimensionalFEM analysis", the 13th world conference of earthquake engineering,Paper No.1354.

[12] Kaung, J. S., and Wong, H. F., (2011), "Effectiveness of HorizontalStirrups in Joint Core for Exterior Beam-Column Joints with NonseismicDesign”, Procedia Engineering, Vol. 14, pp. 3301-3307.

[13] Kim, J., and Lafave, J. M., (2007), "Key influence parameters for thejoint shear behaviour of reinforced concrete (RC) beam-columnconnections", Engineering Structures, Vol. 29, pp. 2523-2539. 
[14] Kiran, R., and Genesio, G., (2014), “A case study on pre 1970sconstructed concrete exterior beam-column joints”, Case Studies inStructural Engineering, Vol.1, pp. 20-25.

[15] Kularni, S. M., and Patil, Y. D., (2013), “A Novel ReinforcementPattern for Exterior Reinforced Concrete Beam-Column Joint”,Procedia Engineering, Vol. 51, pp. $184-193$.

[16] Kusuhara, F., and Shiohara, H., (2008), "Tests of R/C Beam-ColumnJoint with Variant Boundary Conditions and Irregular Details onAnchorage of Beam Bars”, the 14th world conference of earthquakeengineering.

[17] Lee, J. Y., Kim, J. Y., and Oh, G. J., (2009), "Strength deteriorationof reinforced concrete beam-column joints subjected to cyclicloading”, Engineering Structures, Vol. 31, pp. 2070-2085.

[18] Lee, J. Y., Kim, J. Y., and Oh, G. J., (2009), “Strength deteriorationof reinforced concrete beam-column joints subjected to cyclicloading”, Engineering Structures, Vol. 31, pp. 2070-2085.

[19] Masi, A., Santarsiero, G., Lignola, G. P., and Verderame, G. M.,(2013), "Study of the seismic behavior of external RC beam-columnjoints through experimental tests and numerical simulations”,Engineering Structures, Vol. 52, pp. 207-219.

[20] Megget, L. M., Barton, M. B., and Fenwick, R. C., (2004), "Seismicdesign and behavior of external reinforced concrete beam-columnjoints using 500E grade steel reinforcing”, the 13th world conferenceof earthquake engineering, Paper No. 3472.

[21] Murakami, H., Fujii, S., Ishiwata, Y., and Morita, S., (2000), "Shearstrength and deformation capacity of interior RC beam-column joint subassemblage", the 12th world conference of earthquakeengineering, Paper No. 679.

[22] Okano, H., Mukai, T., Nomura, S., and Suganuma, T., (2004),“Experimental study on the failure behavior of RC exterior beamcolumnjoint at top floor", the 13th world conference of earthquakeengineering, Paper No. 378.

[23] Owada, Y., (2000), "Three dimensional behaviours of reinforcedconcrete beamcolumn joint under seismic load", the 12th worldconference of earthquake engineering, Paper No. 707.

[24] Park, S., and Mosalam, K. M., (2012), "Parameters for shear strengthprediction of exterior beam-column joints without transversereinforcement”, Engineering Structures, Vol. 36, pp. 198-209.

[25] Sharma, A., Reddy, G. R., Eligehausen, R., and Vaze, K. K., (2011),“Strength and ductility of RC beam-column joints of non-safety relatedstructures and recommendations by national standards”, NuclearEngineering and Design, Vol. 241. pp. 1360-1370.

[26] Zhou, J., Hirosawa, M., Konda, T., and Shimizu, Y., (2000) "Effect ofthe torsional moment on the shear strength of reinforced concretecolumns due to 
eccentric jointing of beam to column", the 12th worldconference of earthquake engineering, Paper No. 859.

[27] Fumio K., Keiko A., Hitoshi S. and Shunsuke O. (2004) "Tests Of Reinforced Concrete Interior Beam-ColumnJoint Subassemblage With Eccentric Beams" 13th World Conference on Earthquake Engineering, Paper No. 185.

[28] Burcu B. and James K. (2004) "Experimental Investigation of Eccentric ReinforcedConcrete Beam-Column-Slab Connections UnderEarthquake Loading",13th World Conference on Earthquake Engineering, Paper No. 2150.

[29] A.W. Beeby, F. Fathibitaraf,(2001) "Membrane Effect In The Reinforced Concrete Frames-A Proposal ForChange In The Design of Frames Structures", Engineering Structures, Vol. 23 PP.82-93.

[30] A. Benavent, X. Cahís, R. Zahran (2009), "Exterior Wide Beam_Column Connections In Existing RC Frames Subjected ToLateral Earthquake Loads" Engineering Structures Vol.31 , PP.1414_1424.

[31] A.M. Elsouri, M.H. Harajli(2013), "Seismic Response of Exterior RC Wide Beam-Narrow Column Joints:Earthquake-Resistant Versus As-Built Joints", Engineering Structures vol.57pp.394-405.

[32] R. P. Dhakala, T. Panb, P. Irawanb, K. Tsaic, K. Linc, C. Chen, (2005) , "Experimental Study on The Dynamic Response of Gravity-DesignedReinforced Concrete Connections "Engineering Structures vol.27, PP. 75-87.

[33] T.Eom, H. J. Hwang, and H. Park, (2015) "Energy-Based Hysteresis Model for Reinforced ConcreteBeam-Column Connections"ACI Structural Journal, V. 112, No. 2, pp157-166.

[34] T. El-shafiey, A. Atta, H.Afefy and M.Ellithy (2015) "Experimental Study of RC Exterior BeamcolumnJoint Subjected to TorsionalMoment" International Conference on Advances in Structural and Geotechnical Engineering ICASGE'15, paper no.?

[35] L. N. Lowes and A.Altoontash (2003)"Modeling Reinforced-Concrete BeamColumn JointsSubjected to Cyclic Loading" Journal of Structural Engineering, ASCE, Vol. 129, No. 12, pp 1686-1697.

[36] A.avojcováa, M.Morav, F.Bahledaa, J.Joštb(2014) "Experimental Verification of Reinforced Concrete Member underCyclic Loading "Procedia Engineering vol.91 PP.262 - 267.

[37] S.H. Luk and J.S. Kuang (2012)"Seismic Behaviour of RC Exterior Wide Beam Column Joint " 15th World Conference on Earthquake Engineering, Paper No. ?.

[38] T. Han, P. H. Feenstra, and S. L. Billington (2003) "Simulation of Highly Ductile Fiber-Reinforced Cement-Based Composite Components Under Cyclic Loading"ACI Structural Journal, V. 100, No. 6pp.749-759.

[39] Y.Y. Chang, H.Z. Deng, D. T. Lau, S. Ostovari, K.C. Tsai, and H.A. Khoo (2004) "A Simplified Method for Nonlinear Cyclic Analysis ofReinforced Concrete 
Structures: Direct And EnergyBased Formulations"13th World Conference on Earthquake Engineering, Paper No. 2830.

[38] A.K.Kaliluthin, D.S.Kothandaraman, T.S.Suhail (2014), "A Review on Behavior of Reinforced Concrete Beam-Column Joint" International Journal of Innovative Research in Science,Engineering and Technology, Vol. 3, Issue 4, pp. 11299-11312.

[39] A. R. M. Ahmed , M. M. Rashwan and L. K. Idriss (2012) " Static Behaviour of Different Types of R.C Beam-Column Connections as Affected By Both Value of Acting Axial Normal Force and Grade of Used Concrete (Theoretical Study) " journal of Engineering Sciences, Assiut University, Faculty of Engineering, Vol. 41, No. 2, PP.321-364.

[40] Z. Li, G. D. Hatzigeorgiou (2012) "Seismic Damage Analysis of RC Structures Using Fiber Beam-Column Elements " Soil Dynamics and Earthquake Engineering Vol 32 PP.103-110.

[41] A. DalalBashi and D. Mostofinejad (2011) "Numerical Investigation on The Behaviour of FRP-Retrofitted RC Exterior Beam Column Joint Under Cyclic Loads " IJST, Transaction of Civil and Environmental Engineering, Vol.35, No.C1 , PP.35-50.

[42] H.J. Hwang, H. Park, W. Choi, L. Chung, and J. Kim (2014) " Cyclic Loading Test for Beam-Column Connections with600 MPa (87 ksi) Beam Flexural Reinforcing Bars " ACI Structural Journal, Vol. 111, No. 4, PP.913-923.

[43] British standard BS 8110

[44] Standard Association of New Zealand, New Zealand Standard Code of Practice for the Design of Concrete Structures, NZS 3101, part2,2006. 